http://jmscr.igmpublication.org/home/ ISSN (e)-2347-176x ISSN (p) 2455-0450

crossref DOI: https://dx.doi.org/10.18535/jmscr/v7i11.19

\title{
A Case of ANCA Negative Granulomatosis with Polyangitis Presenting with Peripheral Vascular Disease
}

\author{
Authors \\ Nagamounika Kothapalli ${ }^{1}$, Devi Vinaya Malla $^{2}$, A. Krishna Murthy ${ }^{3}$
}

\begin{abstract}
Granulomatous with Polyangiitis (GPA) rarely presents as the peripheral vascular disease is an early manifestation. Most of the cases of GPA have ANCA positive (90\%), and 10\% are ANCA negative. A case of 32 yr old female who presented with painful gangrene of digits of both upper limb and lower limb and purpura on the lower leg and nasal crusting. CT angiogram of upper limbs shown radial and ulnar cut off and lower limbs narrowed lumen and non-visualisation of the posterior tibial artery. HRCT chest shows focal consolidation and cavitary lesions and soft tissue nodules in the right middle and lower lobes suggestive of granulomatous etiology. biopsy of skin shown vessels occluded with thrombi and transmural inflammation of vessel wall and renal involvement in the form of albuminuria, ANCA were negative. In view of clinical features and HRCT findings and biopsy reports diagnosed as ANCA negative GPA. According to $A C R$ criteria, nasal involvement, lower respiratory tract involvement, renal involvement, and ANCA positivity, 2/4 is enough to diagnose GPA. In our case, three of them are seen. Patient was started on steroids and cyclophosphamide therapy; there was no progression of gangrene, and patient shown symptomatic improvement after treatment. There were less than 20 reported cases of GPA presenting as peripheral vascular disease. Hence GPA should be considered as a possibility in a patient with peripheral vascular disease.
\end{abstract}

\section{Introduction}

Granulomatosis with polyangiitis (GPA) or previously called Wegener's granulomatosis is a systemic autoimmune disorder that involves vessels causing both granulomatosis and polyangiitis. Friedrich Wegener first explained this in $1936^{1}$. It is a multisystem disorder involving small and medium-sized vessels causing vasculitis in every organ possible and give rise manifestations of corresponding involvement ${ }^{2}$. Most cases of GPA are ANCA positive, but $10 \%$ of cases are ANCA negative. There are very fewer cases of GPA presenting as digital gangrene. Hence this is a unique case of ANCA negative GPA presenting as peripheral vascular disease.

\section{Case Report}

A $32 \mathrm{yr}$ old female presented to the hospital with complaints of fever, arthralgia, nasal crusting since six months and 15 dayshistory of blackish discoloration of fingers and toes which are painful. No significant past, family, or personal history present. On examination, she was found to have pallor, reddish discoloration of the conjunctiva, Episcleritis, nasal crusting with ulceration and on filthrum and blackish discoloration of toes and fingers and palpable purpura on the lower limbs, with feeble dorsal is pedis artery pulsations on both sides and absent radial artery pulsations on both sides. On chest examination, mild crepitation was heard on right side and no other significant finding. 


\section{JMSCR Vol||07||Issue||11||Page 109-111||November}

\section{Investigations}

\begin{tabular}{|l|c|c|c|}
\hline HB & $7.2 \mathrm{gm} / \mathrm{dl}$ & S.creatinine & $0.6 \mathrm{mg} / \mathrm{dl}$ \\
\hline TC & 13600 & B.urea & $24 \mathrm{mg} / \mathrm{dl}$ \\
\hline DC & P-70,L-23,E-6,M-1 & T.bilirubin & $0.7 \mathrm{mg} / \mathrm{dl}$ \\
\hline PLATELET & 2.141 lakh/dl & Uric acid & $1.3 \mathrm{mg} / \mathrm{dl}$ \\
\hline PS & $\begin{array}{c}\text { Microcytichypochromicane } \\
\text { mia }\end{array}$ & CUE & $\begin{array}{c}\text { Alb-1+,sugar-nil,4-6 pus cells,2- } \\
\text { 3epithelial cells,no RBC }\end{array}$ \\
\hline ESR & $60 \mathrm{~mm} / \mathrm{hr}$ & $24 \mathrm{hr}$ urinary protein & $960 \mathrm{mg} / 24 \mathrm{Hrs}$ \\
\hline CRP & Positive(70.2mg/l) & Blood C/S & sterile \\
\hline ANA & Negative & HIV & negative \\
\hline p-ANCA & negative & HBsAg & negative \\
\hline c-ANCA & negative & HCV & negative \\
\hline
\end{tabular}
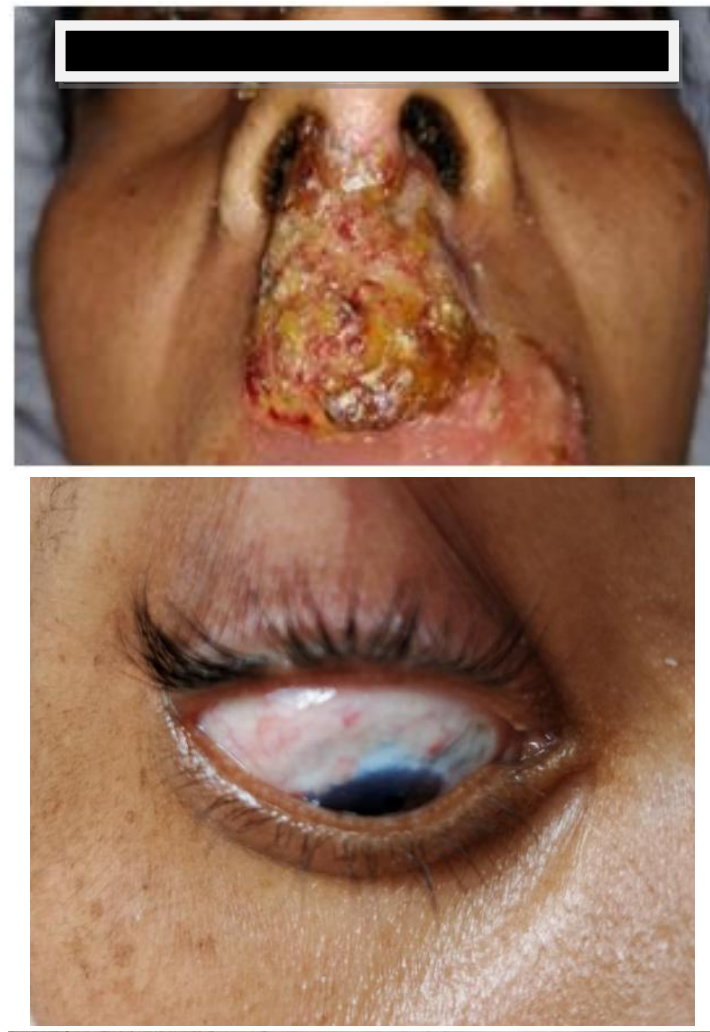

HRCT Chest -patchy air space opacities, focal consolidation, cavitary lesions and nodules noted in bilateral upper lobes and the right middle and lower lobes-diagnostic possibility of granulomatous etiology.

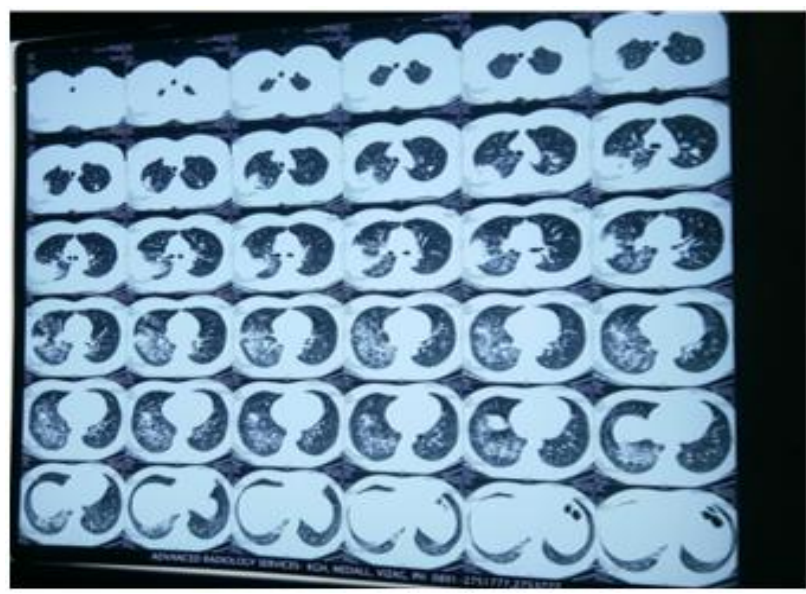

\section{CT Angio of Upper Limbs}

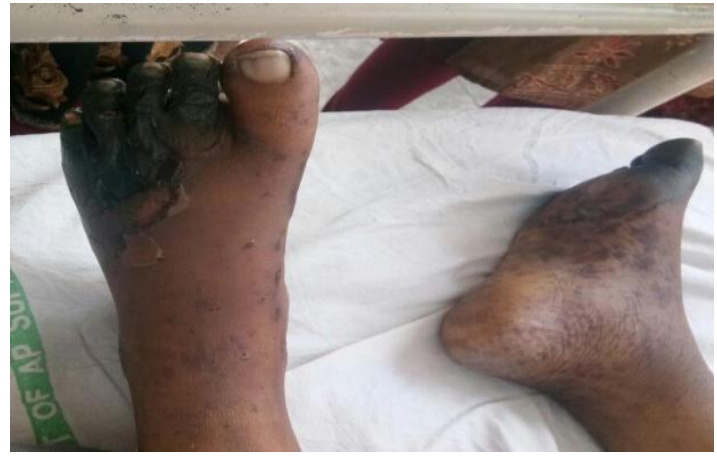

1) Total luminal occlusion with thrombosis of proximal right radial artery involving a segment of $5 \mathrm{~cm}$

2) Total luminal occlusion of right distal ulnar artery and its branches in hand

3) Sparse contrast opacification with near overall luminal narrowing of left distal ulnar artery and its branches
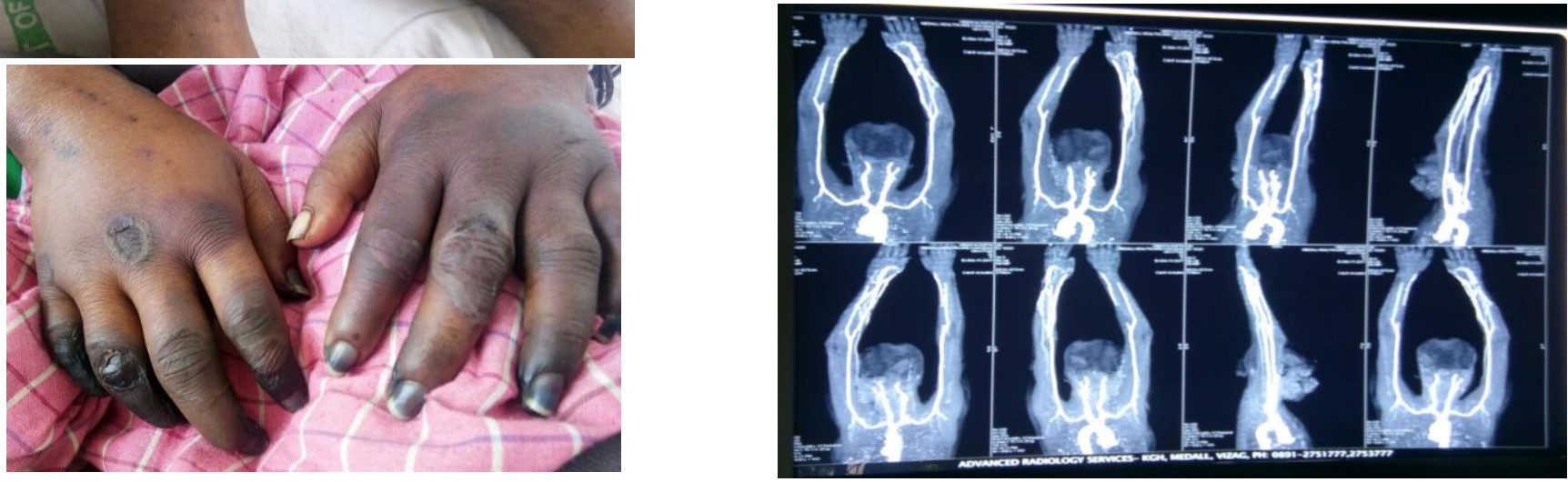


\section{CT Angio of Lower Limbs}

1) the narrowed lumen of upper $1 / 3^{\text {rd }}$ of posterior tibial artery

2) Non visualized the lower $2 / 3^{\text {rd }}$ posterior tibial artery

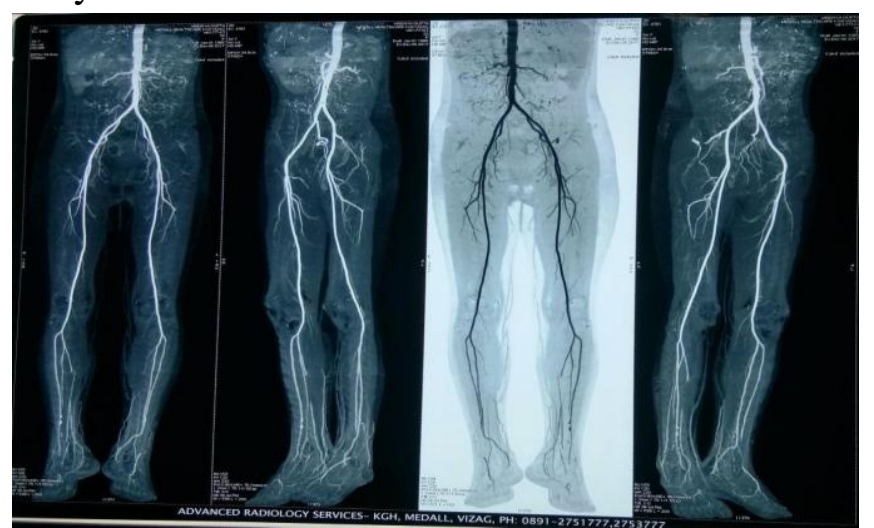

HPE of Skin Biopsy- Dermis showing occluded vessels with thrombi, fibrin material, and transmural inflammatory cells.there is an exhaustion of RBC and perivascular mixed inflammatory cells comprising of neutrophils, lymphocytes and nuclear debris suggestive of vasculitis.

\section{Discussion}

Wegener's granulomatosis was recently changed as GPA in 2011. ACR CRITERIA for GPA includes nasal or oral inflammation, abnormal chest radiograph abnormal urinary sediment, granulomatous inflammation on biopsy of artery ${ }^{4}$ or perivascular area. Two or more of these criteria yielded high sensitivity .Our patient has nasal inflammation and pulmonary nodules, and biopsy showing vasculitis and eye involvement in the form of episcleritis and digital gangrene and palpable purpura. Bilateral or unilateral pulmonary infiltrates are present in nearly $50 \%$ of patients initially, with lung disease eventually developing in $85-90 \%$ of patients. Pleural effusion has also been reported in $12 \%$ of cases ${ }^{5}$.ANCA is mostly positive in $90 \%$ of patients, but in our patient, it is negative, which is seen in 10 percent of cases.

The standard treatment for GPA is cyclophosphamide and high dose corticosteroids for remission induction and less toxic immunosuppressant like azathioprine, leflunomide, methotrexate, or mycophenolatemofetil.

\section{Conclusion}

GPA presenting as digital gangrene is very rare, and ANCA negative in GPA is also unique. There were less than 20 reported cases of GPA presenting as peripheral vascular disease, so patient presenting with peripheral vascular disease, GPA should be considered in evaluating the cases.

\section{References}

1. Wegener F. Übergeneralisierte, septische Gefässerkrankungen. Verh Dtsch Ges Pathol . 1936;29:202-10. [Google Scholar]

2. Falk RJ, Gross WL, Guillevin L, Hoffman GS, Jayne DR, Jennette JC. et al. Granulomatosis with polyangiitis (Wegener's): an alternative name for Wegener's granulomatosis. Arthritis Rheum . 2011;63(4):863-4. [PubMed] [Google Scholar]

3. Jennette JC. Nomenclature and classification of vasculitis: lessons learned from granulomatosis with polyangiitis (Wegener's granulomatosis) Clin ExpImmunol. 2011; 164 Suppl 1:7-10. [PMC free article] [PubMed] [Google Scholar]

4. Tulankar S, Gokhale S, Dharap S, Prabhakar S. Peripheral arterial disease in nondiabetics: Don't miss vasculopathy of specific etiology -nonatherosclerotic (VSENA) in young patients. JAPI 2011;59:217221

5. Cordier JF, Valeyre D, Guillevin L, Loire R, Brechot JM. Pulmonary Wegener's granulomatosis. A clinical and imaging study of 77 cases. Chest. 1990; 97:906-912. [PubMed] [Google Scholar]. 